\title{
Kala Azar- Difficult Yet Diagnosable Entity
}

\author{
Barinder Kaur ${ }^{1}$, Charu Batra Atreja², Bimal K. Agrawal ${ }^{3}$ \\ ${ }^{1}$ Department of Medicine, MM Institute of Medical Sciences and Research, Maharishi Markandeshwar Deemed to be \\ University, Mullana, Haryana, India. ${ }^{2}$ Department of Pathology, MM Institute of Medical Sciences and Research, \\ Maharishi Markandeshwar Deemed to be University, Mullana, Haryana, India. ${ }^{3}$ Department of Medicine, MM Institute \\ of Medical Sciences and Research, Maharishi Markandeshwar Deemed to be University, Mullana, Haryana, India.
}

\section{INTRODUCTION}

Kala azar also called as visceral leishmaniasis is a slowly progressive parasitic infection caused by protozoan of Leishmania genus transmitted by infected bite of female Phlebotomus. ${ }^{(1,2)}$ Known endemic region of the world are rural India, Bangladesh, Sudan, Nepal and Brazil.(3) In India, kala azar is prevalent in hot and humid climates in eastern Indian states with most cases reported from Bihar, Bengal, Jharkhand and Uttar Pradesh, ${ }^{(4)}$ with few sporadic cases reported from sub Himalayan part of north India including Uttarakhand, Jammu and Kashmir and Himachal Pradesh and few cases from Gujrat.(5,6,7) Diagnosis of kala azar is based on clinical suspicion of the disease along with diagnostic tests that include parasitic demonstration in splenic aspirate and amastigote form of LD (Leishmania donovani) bodies in bone marrow aspirate.(8) Splenic aspirate has a very good sensitivity index but is not generally the preferred diagnostic test because of its difficulty technique and risk of fatal haemorrhage, hence bone marrow aspirate is most commonly performed diagnostic test.

Kala azar is endemic in four states of India i.e. Bihar, Uttar Pradesh, West Bengal and Jharkhand. But it can be seen in any part of the country as people move from one place to another to earn their livelihood. Repeated attempts of eliminating this disease has been met with failures. After missing the recent deadline of 2017, Government of India is yet to set a new goal. To succeed all the health professionals should come together to increase awareness about the disease. Here we present a case of a young boy who reported to us with prolonged fever, splenomegaly and pancytopenia. After eliminating other possibilities and as a workup for pyrexia of unknown origin, bone marrow aspiration was done. Initially kala azar was considered as a differential diagnosis, and it was confirmed by demonstrating LD bodies in the marrow aspirate.

\section{PRESENTATION OF CASE}

A 20 years male, permanent resident of Uttar Pradesh presented to our department with chief complaints of fever for 3 months, abdominal discomfort for 1 month, 2 episodes of nasal bleed 3 days back, and black coloured stools for one day. For the past 3 months patient was being treated at his native place where he was transfused with 4 fresh frozen plasma and 4 platelet concentrates 1 month back, but the condition of the patient kept on deteriorating despite their efforts. Subsequently the patient was referred to our tertiary care centre. Patient was admitted in our hospital and initial assessments revealed presence of jaundice and pallor, on per abdomen examination liver was palpable $6 \mathrm{~cm}$ below right costal margin and spleen was palpable $12 \mathrm{~cm}$ below left costal margin, rest of the systems were normal on examination.
Corresponding Author: Dr. Bimal K. Agrawal, Professor,

Department of Medicine, MM Institute of Medical Sciences and Research, Maharishi Markandeshwar Deemed to be University, Mullana-133207, Haryana, India.

E-mail: onlybimal@gmail.com

DOI: $10.14260 /$ jemds $/ 2020 / 71$

Financial or Other Competing Interests: None.

How to Cite This Article:

Kaur B, Atreja CB, Agrawal BK. Kala azardifficult yet diagnosable entity. J. Evolution Med. Dent. Sci. 2020;9(05):312-314, DOI: 10.14260/jemds/2020/71

Submission 25-11-2019,

Peer Review 11-01-2020,

Acceptance 17-01-2020,

Published 03-02-2020. 
Peripheral blood film was suggestive of pancytopenia. Red cell morphology was microcytic hypochromic with moderate anisocytosis, total leucocyte count was $1300 / \mathrm{cmm}$, platelet count was $15,000 / \mathrm{cmm}$. Liver function tests of the patient reported total bilirubin- $4.12 \mathrm{mg} / \mathrm{dl}$, transaminases were elevated with AST of $108 \mathrm{IU} / \mathrm{L}, \mathrm{ALT}-105 \mathrm{IU} / \mathrm{L}$, and albumin 1.3 $\mathrm{g} / \mathrm{dl}$. Blood cultures report was negative and Viral marker serology (hepatitis A, B, C, E and HIV) were also negative. As diagnostic tests for dengue and malaria were also negative, patient was ordered a bone marrow examination on clinical suspicion of Kala Azar (visceral leishmaniasis). The bone marrow picture of the patient showed LD bodies (figure 1). The patient was immediately started on Amphotericin B injections at the dosage of $1 \mathrm{mg} / \mathrm{kg}$ every alternate day, after 5 infusions patient was symptomatically improving but patient left against medical advice and patient did not show up for the remaining dosing and was lost to follow up.

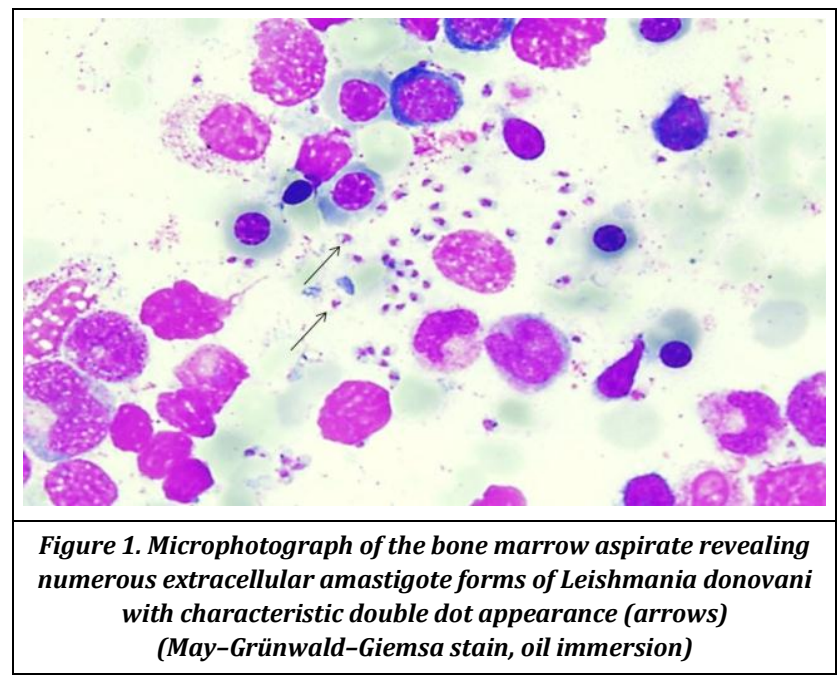

\section{DISCUSSION}

First reported case of kala azar was in Jessore district in Bengal, which is now in Bangladesh, in 1824.(9) It is known endemic disease in 62 countries, there are estimated 500,000 new cases reported annually of which $90 \%$ cases are from countries with rural population like India, Bangladesh, Nepal, Brazil and Sudan, Nearly one half of the cases occur in India.(10)

Kala azar has an incubation period ranging from 10 days to 2 years.(11) Protozoan of visceral leishmaniasis infects the macrophages and monocytes (circulating and fixed phagocytic cells) responsible for immune response in the body. The bite of sand-fly transmits the flagellate promastigote form in the body. The macrophages present in the bone marrow, spleen and liver phagocytose promastigote form and transform it to aflagellate amastigote. This intracellular amastigote form is called as LD (Leishman - Donovan) Body. These LD bodies are $2-5 \mu \mathrm{m}$ in length, oval in shape and can be identified by the nucleus along with extranuclear densely stained kinetoplast on microscopy.(12) For the treatment of kala azar liposomal amphotericin B in dosage of $3 \mathrm{mg} / \mathrm{kg} /$ day for 7 days given (1 $1^{\text {st }}$ to $5^{\text {th }}$ day, then $14^{\text {th }}$ and 21 st day). Because of high cost of amphotericin B, sodium stibogluconate has been the preferred treatment agent in India. Recently single dose of $10 \mathrm{mg} / \mathrm{kg}$ of liposomal Amphotericin B is being advocated. Moderate success has also been achieved with oral miltefosine and paromomycin.(13)

Early diagnosis of kala azar has always been difficult especially in non-endemic regions as early infection usually presents with a triad of fever, splenomegaly and pancytopenia which is common in many infectious and non-infectious diseases making it extremely difficult to suspect on initial assessment.(14,15) Via this case report we want to emphasize on the fact that clinical suspicion in such cases is extremely important, lack of diagnosis can lead to fatal outcomes in such patients. Our patient was initially treated at his hometown where he underwent multiple diagnostic tests and various treatments but a diagnosis was not reached upon. We would also like to stress upon the importance of geographical information of the patient like in our case Haryana state is not an endemic region for kala azar however our patient was a resident of Uttar Pradesh state which is a known endemic region for kala azar. Similarly, various cases have been reported about patients from these endemic regions working outside of the state or with history of travel to these endemic areas, presenting in non-endemic regions. Kala azar may be difficult to diagnose, but it is definitely treatable.

\section{REFERENCES}

[1] Extent of problem of Kala-Azar in India: National Vector Borne Disease Control Programme (NVBDCP), MOHFW. Government of India. http://nvbdcp.gov.in/

[2] Lainson R. The American leishmaniasis: some observations on their ecology and epidemiology. Trans R Soc Trop Med Hyg 1983;77(5):569-96.

[3] Murray HW. Kala-azar-progress against a neglected disease. N Engl J Med 2002;347(22):1793-4.

[4] Sharma U, Redhu NS, Mathur P, et al. Re-emergance of visceral leishmiasis in Gujrat, India. J Vector Borne Dis 2007;44(3):230-2.

[5] Naik SR, Rao PN, Datta DV, et al. Kala-azar in northwestern India: a study of 23 patients. Trans R Soc Trop Med Hyg 1979;73(1):61-5.

[6] Singh S, Biswas A, Wig N, et al. A new focus of visceral leishmaniasis in sub-Himalayan (Kumaon) region of northern India. J Commun Dis 1999;31(2):73-7.

[7] Raina S, Mahesh DM, Kaul R, et al. A new focus of visceral leishmaniasis in the Himalayas, India. J Vector Borne Dis 2009;46(4):303-6.

[8] Sundar S, Sahu M, Mehta $H$, et al. Non-invasive management of Indian visceral leishmaniasis: clinical application of diagnosis by K39 antigen strip testing at a Kala-Azar referral unit. Clin Infect Dis 2002;35(5):581-6.

[9] Sengupta PC. History of Kala-Azar in India. Indian Med Gaz 1947;82(5):281-6.

[10] Ho M, Siongok TK, Lyerly WH, et al. Prevalence and disease spectrum in a new focus of visceral leishmaniasis in Kenya. Trans R Soc Trop Med Hyg 1982;76(6):741-6.

[11] Gulati S, Paljor HP, Pandit S, et al. Kala-Azar without splenomegaly. Annals of Tropical Medicine and Public Health 2009;2(2):57-60.

[12] Varma N, Naseem S. Hematologic changes in visceral leishmaniasis/Kala-Azar. Indian J Hematol Blood Transfus 2010;26(3):78-82. 
[13] Meyerhoff A. U.S. Food and Drug Administration approval of AmBisome (liposomal amphotericin B) for treatment of visceral leishmaniasis. Clin Infect Dis 1999;28(1):42-8. discussion 49-51.

[14] Voulgari PV, Pappas GA, Liberopoulos EN, et al. Visceral leishmaniasis resembling systemic lupus erythematosus. Ann Rheum Dis 2004;63(10):1348-9.
[15] Agrawal BK, Marwaha S, Bhatnagar M, et al. Association of systemic lupus erythematosus and beta Thalassaemia trait-a case report. Journal of Clinical and Diagnostic Research: JCDR 2016;10(6):OD03-4 